\title{
Esterification Reactions of Lipase in Reverse Micelles
}

\author{
Douglas G. Hayes and Erdogan Gulari* \\ Department of Chemical Engineering, The University of Michigan, \\ Room 3074 H. H. Dow Building, Ann Arbor, Michigan 48109
}

Accepted for publication September 29, 1989

\begin{abstract}
The activities of lipase from Candida cylindracea and Rhizopus delemar have been investigated in water/AOT/ iso-octane reverse micellar media through the use of two esterification reactions: fatty acid-alcohol esterification and glyceride synthesis. Such media promotes the occurrence of these two lipase-catalyzed reactions due to its low water content. The effect of various parameters on the activity of lipase from $C$. cylindracea in reverse micelles was determined and compared to results where alternate media were employed. It was observed that the structure of the media, as dictated by the type and concentration of the substrates and products and by the water/AOT ratio, $w_{0}$, had a strong impact on enzyme activity. Strong deactivation of both lipase types occurred in reverse micelles, especially in the absence of substrates and for $w_{0}$ values greater than 3.0. Glyceride synthesis was realized with lipase from $R$. delemar, but not with that from $C$. cylindracea; the temperature and concentration of substrates and water strongly dictated the reaction rate and the percent conversion.
\end{abstract}

\section{INTRODUCTION}

Reverse micelles have been studied and applied in a variety of research areas in the past decade. Moreover, reverse micelles, nanometer-sized water droplets dispersed in organic media by the action of surfactants, have unique properties which enhance their utility. ${ }^{1,2}$ The anionic double-tailed surfactant AOT [Sodium bis-(2-ethylhexyl) sulfosuccinate] has been frequently employed in the study of reverse micelles. Unlike most surfactants, AOT, because of its wedge-shaped molecular geometry, ${ }^{2}$ does not require additional amphiphiles or cosurfactants for the formation of reverse micelles. Applications of reverse micelles include tertiary oil recovery, ${ }^{3}$ extraction of metals from raw ores ${ }^{4}$ and of biomolecules from fermentation broths, ${ }^{5}$ and in vivo drug delivery. ${ }^{6}$ Also, reverse micelles have found use as media for hosting enzymatic reactions. ${ }^{7,8}$ For example, many enzymatic reactions such as steroid modification ${ }^{9}$ require biphasic media: polar media for the solubilization of enzymes and organic media for solubilizing apolar substrates. Compared with other biphasic media such as oilin-water $(\mathrm{O} / \mathrm{W})$ emulsions, reverse micelles provide a

\footnotetext{
* To whom all correspondence should be addressed
}

larger polar/apolar interfacial area, hence improving the interaction between enzyme and substrate.

Biphasic media are also needed for hosting many of the reactions of the enzyme lipase, two of which are diagrammed in Figure 1. Reverse micelles have been employed for lipase-catalyzed hydrolysis of triglycerides, ${ }^{10-13}$ one of the enzyme's primary function in vivo, with results showing comparable enzyme activity to that encountered in alternate media. In addition, due to its optical clarity and ease of preparation, reverse micellar solution has been suggested as the media of choice for assaying lipase's activity. ${ }^{14,15}$ However, the most useful application of reverse micelles with lipase may be for hosting the reverse of this reaction: glyceride synthesis (reaction II of Fig. 1), as well as transesterification: the replacement of fatty acids groups in triglycerides. These reactions can produce lipids of unique structure and properties that would be of interest to industries such as food and cosmetics. ${ }^{16}$ For glyceride synthesis to take place, reaction media must have low water content to hinder the reverse reaction: hydrolysis, from occurring. For this reason, glyceride synthesis has been investigated in nonpolar heterogeneous media, where lipase is immobilized by adsorption onto a solid surface, with results indicating feasibility. ${ }^{16-18}$ But use of these reaction schemes has significant disadvantages, including long and difficult preparation procedures, enzyme desorption from supports, and low specific reaction rates (Rate of product formation per quantity of enzyme). It has been shown only recently that reverse micellar media can host transesterification $^{19-22}$ and glyceride synthetic ${ }^{23,24}$ reactions of lipase. More information is desired on how reverse micelles affect the reaction kinetics; more specifically, the activity and stability of lipase, as well as the localization of substrates. This is the aim of our investigation.

\section{MATERIALS AND METHODS}

\section{Materials}

AOT (ca. 98\% pure) was purchased from Fluka (Ronkokoma, NY), purified by an extraction procedure similar to the one developed by Martin and Magid, ${ }^{25,26}$ and 
1 .

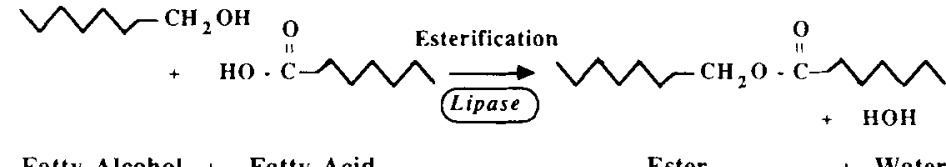

Fatty Alcohol + Fatty Acid

Ester

+ Water

II.

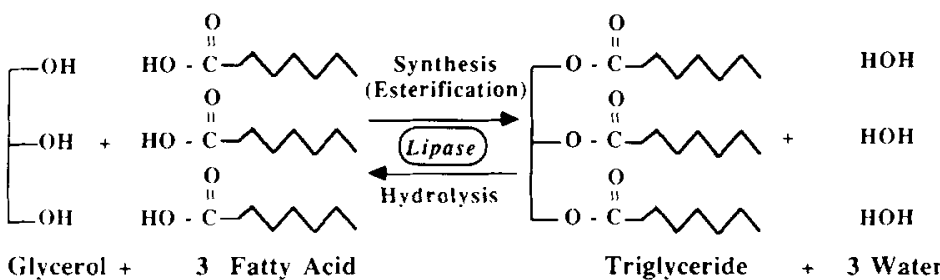

Figure 1. Two examples of esterification reactions with lipase: (I) fatty acid-alcohol esterification; (II) glyceride synthesis.

stored in a dessicator. Lipase (EC 3.1.1.3) from Candida cylindracea (Type VII-S) was purchased from Sigma (St. Louis, MO) and used without further purification. Sigma's purification process for this enzyme contains two desalting steps; thus, the lyophilized enzyme powder is essentially salt-free. Lipase from $R$. delemar was purchased from Fluka and also used without further purification. The olive oil employed was "Bertolli Lucca" from Alivar S.p.A. (Novara, Italy). All alcohols, organic solvents (isooctane, e.g.), fatty acids, buffer salts, and assay reagents used were of high purity $(>99 \%)$. Deionized water was used throughout. Analytical equipment employed in this investigation include a UV-vis Spectrophotometer (Hewlett-Packard model 8451A), a pH-meter (Beckman model 45) and a gas chromatograph (Hewlett-Packard model 5890A with model 3393 integrator).

\section{Methods}

For each of the two reactions investigated here (Reactions I and II of Fig. 1), two solutions were prepared. The first was of AOT and fatty acid (dodecanoic acid in most cases) in isooctane (plus glycerol for reaction II); the concentration of the two former components was typically $100 \mathrm{~m} M$. The second solution was of lipase in aqueous buffer $(50 \mathrm{mM}$ phosphate, $\mathrm{pH} 6.88 \pm 0.1$, unless otherwise specified), typically at a concentration of $2 \mathrm{mg} / \mathrm{mL}$. After their preparation, a small aliquot of the second mixture was injected into the first; with gentle agitation for 0.5 $2 \mathrm{~min}$, the solution's appearance changed from cloudy to clear, indicating the formation of reverse micelles. This initiated reaction II. For reaction I, alcohol was then added to begin the reaction. All reactions were conducted at room temperature $\left(24 \pm 2^{\circ} \mathrm{C}\right)$ unless noted otherwise.

For Reaction I, the rate was determined by tracing the depletion of fatty acid substrate using the spectrophotometric assay of Lowry and Tinsley, ${ }^{27}$ in similar fashion to that performed by Han and Rhee. ${ }^{28}$ Moreover, aliquots of the reaction mixture were taken at selected times and assayed for fatty acid content. For all of our reaction I experiments, the initial rate of substrate depletion, " $V_{\text {init }}$ " was linear, as predicted by Michaelis-Menten kinetics for high initial rate of substrate-enzyme ratios. It is this value, normalized by the overall enzyme concentration, " $[E]_{\mathrm{ov}}$ " in milligrams of enzyme sample per milliliter, that was used to represent lipase activity in this investigation. To increase the accuracy of our findings, each set of results shown came from the same run, with a run consisting of a series of reactions performed simultaneously, under similar operating conditions, and often with common aqueous and/or organic bulk solutions. Moreover, the error for activity values obtained within the same run was under $5 \%$, while variance increased to $20 \%$ for lipase from $C$. cylindracea and $6 \%$ for lipase from $R$. delemar for values obtained between runs.

Reaction I was used for determining the stability of lipase in reverse micelles. For these experiments, reverse micellar media containing lipase and fatty acid were prepared in bulk and incubated at room temperature. Enzyme activity was assayed as described above for aliquots of the incubation mixture at selected times. For comparison, the stability of lipase in bulk aqueous media was also determined using reverse micelles as the assaying media.

Reaction II was monitored using gas chromatography (GC) on a capillary column of $65 \%$ methyl phenyl silicone (polyimide clad), $0.15 \mu \mathrm{m}$ thickness, $0.32 \mathrm{~mm}$ i.d., and $25 \mathrm{~m}$ length from Quadrex (New Haven, CT). Monoglycerides (MG's) and diglycerides (DG's) were converted to TMS ethers using a procedure similar to that developed by Brengartner ${ }^{29}$ : aliquots of reaction media, internal standard solution, chloroform, and derivitizing reagent [BSTFA/ chlorotrimethylsilane at $99 / 1(\mathrm{v} / \mathrm{v})]$ were mixed and heated at $80^{\circ} \mathrm{C}$ for $10 \mathrm{~min}$. (This terminated the reaction.) Then $1-1.5 \mu \mathrm{L}$ were then injected into the GC. The temperature program used $\left(100-365^{\circ} \mathrm{C}\right.$ at a gradient of $10^{\circ} \mathrm{C} / \mathrm{min}$., followed by an isothermal hold at $365^{\circ} \mathrm{C}$ for $4 \mathrm{~min}$.) allowed for elution of fatty acids and all products (MG- and DG-TMS ethers and triglycerides, TG's) and separated MG and DG positional isomers. Concentrations are reported in terms of GC peak area normalized by the peak area of the internal standard.

The hydrodynamic or Stokes radii $\left(R_{h}\right)$ of non-proteincontaining ("empty") reverse micelles was determined by Dynamic Light Scattering (DLS), with $R_{h}$ being defined as 
the distance from the center of the water pool to the outside edge of the surfactant layer (see ref. 30 for more detail). The apparatus used for DLS is similar to that mentioned in the literature $e^{26.31}$ and features an argon laser (Lexel, Palo Alto, CA) and a 128-channel digital correlator (Brookhaven Instruments, Ronkonkoma, NY), the latter of which determines the electric field autocorrelation function, $g^{(l)}(\tau)$, from measurements of scattered intensity. From this function the translational average diffusion coefficient, $D_{z}$, is determined ${ }^{32}$ :

$$
\left|g^{(l)}(\tau)\right|=\exp \left(-D_{z} Q^{2} \tau\right),
$$

where $Q=(4 \pi n / \lambda) \sin (\theta / 2)$ is the magnitude of the scattering vector; $\lambda$ is the wavelength of incident light ( $514.5 \mathrm{~nm}$.), $\Theta$ is the scattering angle $\left(90^{\circ}\right)$, and $n$ is the solution refractive index. This equation is valid for monodisperse populations of colloidal aggregates present in dilute concentrations. According to the literature, ${ }^{33}$ at our concentrations of water and AOT the dilution assumption is valid. From $D_{z}, R_{h}$ can be calculated from the Stokes-Einstein equation:

$$
R_{h}=k T / 6 \pi \mu D_{z},
$$

where $k$ is the Boltzman constant; $T$ is the absolute temperature; and $\mu$ is the solution viscosity. This equation applies only for spherical particles, of which description holds true for reverse micelles. ${ }^{1}$ Results were highly repeatable, with errors in $R_{h}$ values being within $\pm 0.2 \mathrm{~nm}$. To check the assumption of monodispersity, data were examined with the method of cumulants. ${ }^{34}$ Except for one set of data (to be discussed below), results here showed low indeces of polydispersity $(<0.15)$. For the one set of polydisperse samples, the values of $R_{\hbar}$ reported are derived from the method of cumulants; all other radii values are derived using eqs. (1) and (2).

The $\mathrm{pH}$ of micellar-encapsulated water, $\mathrm{pH}_{w p}$, was estimated using the ${ }^{31} \mathrm{P}-\mathrm{NMR}$ technique explained in the literature. ${ }^{35.36}$ The instrument used was a model WM360 spectrometer from Bruker at $145 \mathrm{MHz}$. The spectral width was $2500 \mathrm{~Hz}$; accumulations were from 5 to 500 scans. Also, a $\mathrm{D}_{2} \mathrm{O}$ lock was employed.

\section{RESULTS AND DISCUSSION}

Results for the first four parts of this section were obtained employing primarily reaction I (see Fig. 1) and lipase from $C$. cylindracea. In the fifth section results of reaction II with lipase from $R$. delemar are discussed.

\section{Effect of Fatty Acid Substrate on Lipase Activity}

Table I compares the effect the fatty acid type has on the rate of product formation for two different reaction systems: $\mathrm{O} / \mathrm{W}$ emulsions ${ }^{37}$ and reverse micelles. Despite the difference in reactions and operating conditions (see caption for Table 1), the effect imposed by the fatty acid type appears to be similar in both media; moreover, no significant difference in substrate specificity is apparent. Dynamic Light Scattering (DLS) measurements of micellar size for fatty-acid-containing reverse micelles show little difference due to the fatty acid types listed in Table I, indicating each is of near equal effectiveness as a cosurfactant; i.e., each equally penetrates into the surfactant layer (apparently the site of the reaction, as discussed below). Thus, it appears that fatty acid substrate specificity is inherent of the activity of the enzyme and is not altered by encapsulation in reverse micelles.

\section{Effect of the Buffer Composition on Activity}

Figure 2 compares pH profiles for the activity of lipase in emulsion $^{38}$ and reverse micellar media. As can be seen, the enzyme in each media is quite active between $\mathrm{pH} 4$ and 8 , but rapidly loses activity outside of this range. Similarly to the comparison made in the previous section, little difference exists between $\mathrm{pH}$ profiles of the two reaction media; thus, encapsulation in reverse micelles does not affect lipase's sensitivity to $\mathrm{pH}$. It should be mentioned that since the water in reverse micelles has different properties than that of bulk water, ${ }^{2}$ the $\mathrm{pH}$ inside the water pools, $\mathrm{pH}_{\mathrm{wp}}$, may be different than that of the same solution measured in bulk, $\mathrm{pH}_{b}$. Although $\mathrm{pH}_{\mathrm{wp}}$ cannot be directly measured, its difference from $\mathrm{pH}_{b}$ is significantly lessened when

Table I. The effect of fatty acid type on the activity of lipase from $C$. cylindracea for $\mathrm{O} / \mathrm{W}$ (oilin-water) emulsion and reverse micellar media.

\begin{tabular}{lcc}
\hline $\begin{array}{c}\text { Fatty acid type } \\
\text { IUPAC (common) nomenclature }\end{array}$ & $\begin{array}{c}\text { Relative rate } \\
\text { in } \mathrm{O} / \mathrm{W} \text { emulsions }\end{array}$ & $\begin{array}{c}\text { Relative rate }^{\mathrm{a}} \\
\text { in reverse micelles }^{\mathrm{c}}\end{array}$ \\
\hline cis-9-Octadecenoic (oleic) acid & 1.02 & 1.07 \\
Octanoic (caprylic) acid & $\mathrm{NA}$ & 1.02 \\
Dodecanoic (lauric) acid & $1.00^{\mathrm{a}}$ & $1.00^{\mathrm{a}}$ \\
Hexadecanoic (palmitic) acid & 0.851 & 0.686 \\
Tetradecanoic (myristic) acid & 0.769 & 0.646 \\
Octadecanoic (stearic) acid & 0.496 & 0.540 \\
\hline &
\end{tabular}


the buffer is "strong," meaning its $\mathrm{pH}$ is near the $\mathrm{pK}_{a}$ of the buffer salt, and when the size of the water pools are intermediate-to-large, as indicated by $\mathrm{H}_{2} \mathrm{O} / \mathrm{AOT}$ mole ratios greater than 7.0 (This ratio, given the symbol " $w_{0}$," is directly proportional to the water droplet radius, as will be discussed in the next section). ${ }^{35,36}$ Since each experiment used to produce reverse micelle data in Figure $2 \mathrm{em}$ ploys a "strong buffer" and a $\mathrm{H}_{2} \mathrm{O} / \mathrm{AOT}$ ratio of 8.0 , we believe the $\mathrm{pH}_{b}$ value of each buffer reasonably approximates the actual $\mathrm{pH}$ of the enzyme's microenvironment, $\mathrm{pH}_{\mathrm{wp}}$. In addition, the AOT purification used removes a significant proportion of an acidic impurity which can effect the value of $\mathrm{pH}_{\mathrm{wp}}$. ${ }^{39}$ We used the ${ }^{31} \mathrm{P}$-NMR technique $^{35,36}$ to estimate $\mathrm{pH}_{\mathrm{wp}}$ for "empty" (non-proteincontaining) reverse micelles at the conditions for $w_{0}$ and substrate ratio listed in the caption of Figure 2 and received inconclusive results. For $100 \mathrm{mM}$ phosphate at $\mathrm{pH}$ $\sim \mathrm{pK}_{a}$, the difference between $\mathrm{pH}_{b}$ and $\mathrm{pH}_{\mathrm{wp}}$ was within 0.1 units; however, for all other buffers measured (e.g., $200 \mathrm{~m} M$ citrate $/ 100 \mathrm{~m} M$ phosphate at $\mathrm{pH}_{b}=6.48$, $100 \mathrm{~m} M \mathrm{MES} / 100 \mathrm{~m} M$ phosphate at $\mathrm{pH}_{b}=6.08$, $100 \mathrm{~m} M$ Tris/ $100 \mathrm{~m} M$ phosphate at $\left.\mathrm{pH}_{b}=8.10\right), \mathrm{pH}_{\mathrm{wp}}$ was within 0.2 units of 7.0, i.e., near the $\mathrm{pK}_{a}$ of the probe molecule phosphate. These findings indicate that the probe molecules themselves dictate the micellar $\mathrm{pH}$ and interfere with accurate measurement of $\mathrm{pH}_{\mathrm{wp}}$ for our Figure 2 media. Thus, the ${ }^{31} \mathrm{P}-\mathrm{NMR}$ technique for micellar $\mathrm{pH}$ estimation does not appear to be applicable for our reverse micellar media.

The effect of buffer ionic strength (at constant $\mathrm{pH}_{b}$ ) was also investigated. It was found that ionic strengths (i.e., concentration of phosphate in the buffer) of $0-100 \mathrm{~m} M$ did not affect the enzyme activity, but at higher ionic strengths $(>1 M)$, the activity sharply declined. The cause of this effect is twofold: first, the high ionic strength lessens the solubility and activity of the enzyme (a "salting out" ef-

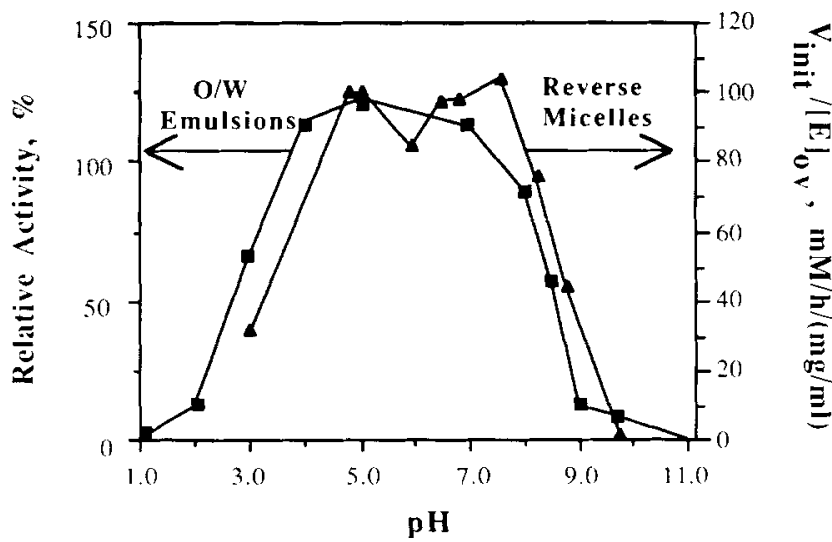

Figure 2. Effect of $\mathrm{pH}$ on activity of lipase from $C$. cylindracea in two different media: (D) $O / W$ emulsion media, the hydrolysis of olive oil at $37^{\circ} \mathrm{C}$; data from ref. $38 ;(\Lambda)$ reverse micellar media, the esterification of dodecanoic acid and $\mathrm{n}$-butanol; $w_{0}=8.0$, [fatty acid] $=100 \mathrm{mM}$, [alcohol] $=250 \mathrm{mM}$. Different aqueous buffers $(50 \mathrm{mM})$ were used for each data point: $\mathrm{pH}_{b} 3.06$ and 4.79 for citrate; $\mathrm{pH}_{b}=5.06$ for maleate; $\mathrm{pH}_{b}=5.99$ for MES; $\mathrm{pH}_{b}=6.49$ for citrate; $\mathrm{pH}_{b}=6.88$ for phosphate; $\mathrm{pH}_{b}=7.57$ for HEPES; $\mathrm{pH}_{b}=8.24$ for tris; $\mathrm{pH}_{b}=8.76$ for glycine; $\mathrm{pH}_{b}=9.78$ for diglycine $-\mathrm{HCl}$. fect); second, the size of the water pools decreases significantly at high ionic strengths, ${ }^{40}$ which lessens catalytic activity when $w_{0}<10$, as will be shown in the next section (the water/AOT ratio, $w_{0}$, was 8.0 for this set of experiments).

\section{Effect of Reverse Micellar Structure on Activity}

As mentioned above, the water/AOT mole ratio, given the symbol $w_{0}$, is directly proportional to the size (radius) of the dispersed water droplets. Figure 3 shows that $w_{0}$ has a significant effect on the activity of lipase. As reported by others for the activity of different micellar-encapsulated enzymes, ${ }^{7,8}$ the plot of activity is bell-shaped with respect to $w_{0}$. The value of $w_{0}$ which optimizes lipase's activity according to Figure 3 is between 10 and 12 , which is similar to optimal $w_{0}$ values reported by Han and Rhee for the same enzyme catalyzing hydrolysis of olive oil (reaction II of Figure 1 in the reverse direction), ${ }^{28}$ for other types of lipase, ${ }^{10,11,23}$ as well as for other micellar-encapsulated enzymes. ${ }^{7}$ This is an especially curious coincidence since, although the value of $w_{0}$ is proportional to micellar size, the micellar radii of these various reaction media are significantly different due to the varying effects imposed by substrates and products. Figure 4 demonstrates the effect various substrates of lipase have upon the size of "empty" reverse micelles, as determined by DLS. Here it is shown that both Han and Rhee's substrate olive oil and our reaction I substrates act as cosurfactants, thus causing a decrease in micellar size. But the degree to which each alters $R_{h}$ is significantly different. In addition, the population of reverse micelles formed with olive oil, in contrast to the other micellar media of Figure 4, is very polydisperse; this is not surprising since olive oil is a mixture of triglycerides of varying shape and size and hence varying degrees of amphiphilicity. Although the actual micellar size and $w_{0}$ of "filled" (i.e., protein-containing) reverse micelles differ from estimates for "empty" reverse micelles, ${ }^{40,41}$ it is reasonable to assume that the cosurfactants/substrates of Figure 4 act upon "filled" and "empty" reverse micelles in a similar fashion; thus, the difference in micellar size

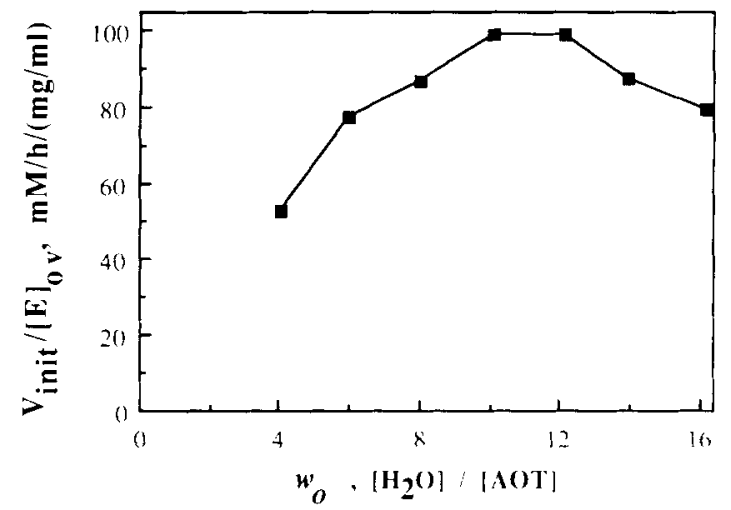

Figure 3. The effect of $w_{0}$ on the activity of lipase from $C$. cylin dracea. Reaction and substrate concentrations as in Figure $2 ; \mathrm{pH}_{\mathrm{b}}=6.88$. 


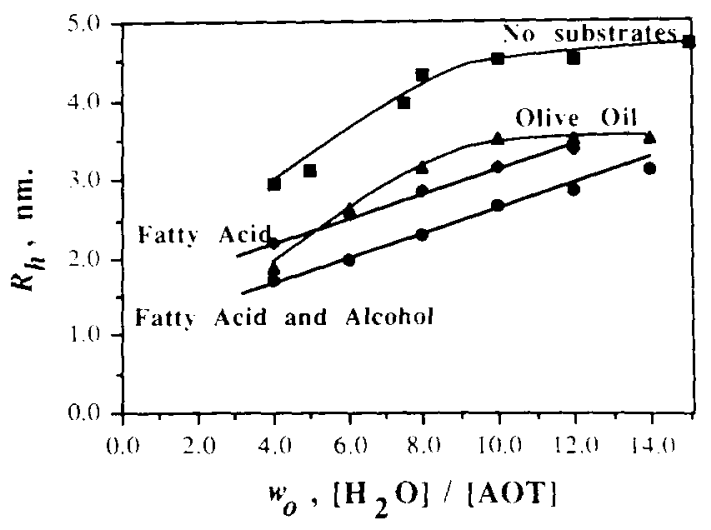

Figure 4. Effect of $w_{0}$ and the presence of substrates on the hydrodynamic radius, $R_{h}$, for water/AOT/isooctane reverse micelles at $T=$ $300 \mathrm{~K}$. Substrates present are: $(\mathbf{D})$ none; $(\Delta)$ olive oil at $10 \%(\mathrm{v} / \mathrm{v})(\mathrm{i} . \mathrm{e}$., similar to media used in ref. 28); (\$) dodecanoic acid at $100 \mathrm{mM}$; (†) dodecanoic acid and $n$-butanol at 100 and $250 \mathrm{mM}$, respectively (i.e., the assay media used in Fig. 2). For all data, [AOT] was $100 \mathrm{mM}$ and the water pseudophase consisted of $50 \mathrm{mM}$ phosphate at $\mathrm{pH}_{b}=6.88$.

shown in Figure 4 for empty micelles probably exists to a similar degree for filled micelles.

Along these same lines, the ester produced by reaction I affects reverse micellar size differently than the substrates. DLS measurements show the reverse micelles of the reaction media increase in radius by over a nanometer by the reaction's completion. Some of the increase in $R_{h}$ can be attributed to the increase in $\left[\mathrm{H}_{2} \mathrm{O}\right]$ caused by the reaction. For example, for the Figure 3 experiments, $w_{0}$ increases from 8.0 to a final value of near 9.0 , which adds roughly $0.3 \mathrm{~nm}$. to $R_{h}$. The rest of the large increase can be attributed to the replacement of fatty acid and alcohol, two equally strong cosurfactants, with a less effective cosurfactant: the ester. Hence, the formed ester, being a bulkier molecule than either of its constituents, cannot penetrate the interface as well due to steric hindrance. Therefore, the ester is a less effective substrate than either alcohol or fatty acid, which helps encourage reaction I to proceed to completion (discussed below). Similar results have been observed for various combinations of fatty acid and alcohol.

The chain length and molecular structure of the alcohol as well uniquely affect micellar structure and hence enzyme activity. This is demonstrated in Figures 5 and 6 . To enhance the explanation of the results in these two figures, we have categorized the various alcohols investigated into three groupings: small, polar alcohols (e.g., methanol, the propanols, and tert-butanol); small, amphiphilic alcohols (e.g., isobutanol and 1-pentanol); and large amphiphilic molecules (e.g., 1-heptanol and 1-decanol). The criteria used for the categorization are based on arguments of molecular structure (e.g., Group 1 molecules are polar while Group 2 and 3 molecules are amphiphilic) and micellar properties (e.g., Group 2 alcohols promote more fluid interfaces while Group 3 alcohols enhance more rigid micellar structure ${ }^{42}$ ). Since Group 1 alcohols are primarily polar and have no significant amphilicity, they do not partition strongly to the interface, but remain inside the water pools and/or the bulk organic solvent as suggested by the DLS

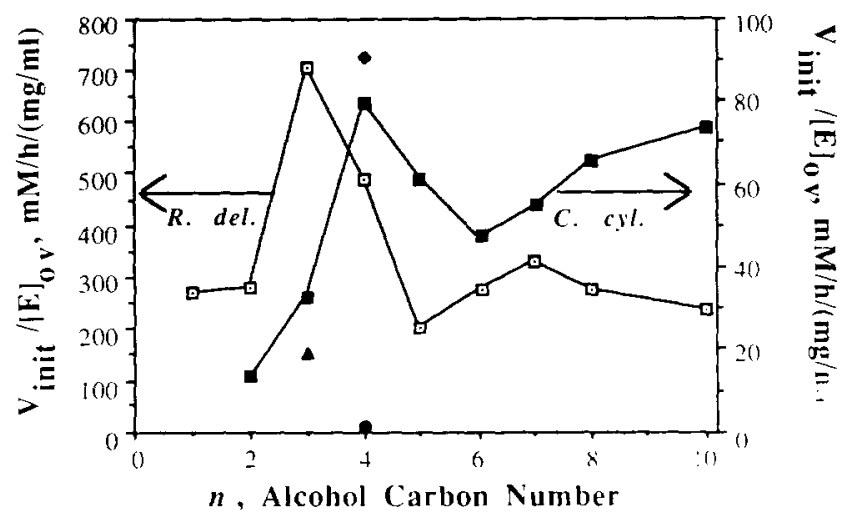

Figure 5. The effect of alcohol carbon number, $n$, on the activity of lipase. Outlined symbols show lipase from $R$. delemar (left-hand side $y$-axis), esterification with cis-9-octadecenoic (oleic) acid; darkened symbols show lipase from $C$. cylindracea (right-hand side y-axis), esterification with dodecanoic acid: $(\square, \square)$ straight-chained alcohols, $\mathrm{CH}_{3}\left(\mathrm{CH}_{2}\right)_{n-1} \mathrm{OH}$; $(\Delta)$ isopropanol, $\left(\mathrm{CH}_{3}\right)_{2} \mathrm{CHOH}$; $(\bullet)$ isobutanol, $\left(\mathrm{CH}_{3}\right)_{2} \mathrm{CHCH}_{2} \mathrm{OH} ;(-)$ tert-butanol, $\left(\mathrm{CH}_{3}\right)_{3} \mathrm{COH}$. Values of $w_{0}$, and substrate concentrations as in Figure 2; $\mathrm{pH}_{b}=6.88$.

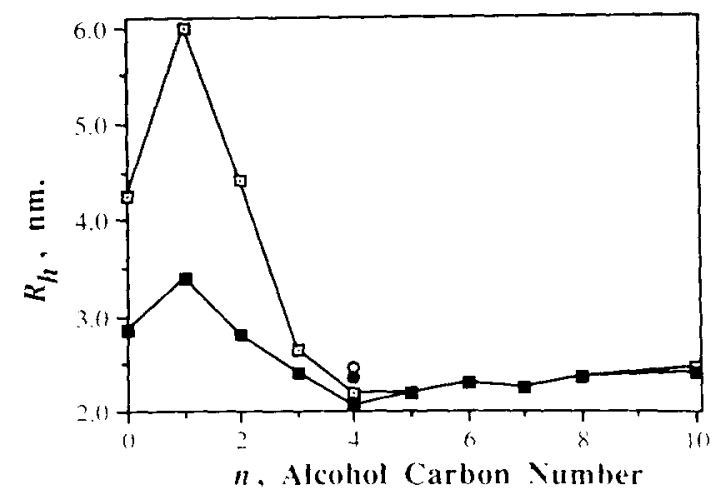

Figure 6. Effect of alcohol carbon number, $n$, on reverse micellar size at $T=300 \mathrm{~K}$ and $w_{0}=8.0$. Outlined symbols show alcohols present as cosurfactants at $250 \mathrm{mM}$; darkened symbols show dodecanoic acid and alcohols present at 100 and $250 \mathrm{mM}$, respectively: $(\square, \square)$ straightchained alcohols; $(O, \bullet)$ tert-butanol. Data shown for $n=0$ are $R_{h}$ values for non-alcohol-containing reverse micellar media; [AOT] and aqueous phase composition are as in Figure 4

data of Figure 6. In addition, their presence in the aqueous pseudophase may deactivate the enzyme. These reasons explain their promotion of relatively small rates as displayed in Figure 5. On the other hand, Group 2 alcohols are more amphiphilic due to their longer hydrocarbon tails and therefore promote an increase in the rate of reaction. In addition, the effect of Group 2 alcohols on relative rates can be linked to their degree of polarity: the order of solubility in water: hexanol $<$ pentanol $<n$-butanol $<$ isobutanol,,${ }^{43}$ mirrors the trends shown in Figure 5 for the activity of lipase from $C$. cylindracea. (The case of data from lipase from $R$. delemar slightly disobeys this rule, as will be discussed below.) Concerning Group 3 alcohols, results from Figure 6 show each has comparable effectiveness as a cosurfactant. Figure 5 indicates that enzyme activity is enhanced as the alcohol size increases from hexanol (i.e., as $n$, the alcohol carbon number, is in- 
creased from 6 upward); this trend diminishes as $n$ reaches 8. The increase in activity reflects the trend that alcohols partition more strongly to the interfacial region as $n$ increases due to lower solubility in bulk organic solvent, ${ }^{44}$ whereas the leveling-off of activity at $n=8$ may be due to less effective penetration of the alcohol within the surfactant layer. Note that in Figure 6 the micellar size slightly increases as $n$ increases from 7 to 10 , indicating that decanol is a poorer cosurfactant, thus supporting the abovementioned claim.

Figure 5 also shows significant differences in straightchained alcohol substrate specificity between the two lipase types. The local maximum and minimum in relative rate at $n$ values of 4 and 6 , respectively, for lipase from C. cylindracea have been shifted one alcohol carbon unit to the left with use of lipase from $R$. delemar; also, differences in trend exist for $n>7$. This can be attributed to different alcohol substrate specificities, as suggested previously, ${ }^{45}$ but to refute this, the alcohol substrate specificity for $R$. delemar in our reaction media differs significantly from data reported for phosphatidylcholine reverse micel$\operatorname{lar}^{23}$ and aqueous ${ }^{45}$ media. Perhaps the difference in results between $C$. cylindracea and $R$. delemar lipases can be explained in terms of differences in enzyme localization in the media microstructure. Moreover, the latter enzyme, which catalyzes polar alcohols such as methanol, ethanol, propanol, and glycerol more favorably and larger alcohols such as octanol and decanol (which apparently penetrate less into the surfactant layer) less favorably, may be located more in contact with the water pool and less with the interface. Further investigation is needed to test the validity of this theory. We have repeated the Figure 5 experiments using different fatty acid types and received similar results to those mentioned above.

The rate of reaction was strongly affected by the ratio fatty acid/alcohol in the media. For all alcohols employed in Figure 5, the larger the value of this ratio, the larger the rate. This can be explained in terms of micellar structure: as more alcohol is added to the media, more partitions to the interface, creating a more fluid interface. ${ }^{46}$ This process displaces the fatty acid from the surfactant layer, thus decreasing its effective concentration in the vicinity of lipase. This trend is the opposite of that reported by Bello et al. for the same enzyme in a nonionic surfactant media, where the alcohol is a necessary cosurfactant as well as a substrate. ${ }^{21}$

According to equilibrium kinetics, a high water content should hinder esterification and promote hydrolysis. Our experiments show for reaction I, the water concentration (at constant $w_{0}$ ) had no effect on the kinetic rate for values up to $1.15 M$ (Higher concentrations were not examined). In addition, although the initial overall concentration of water was larger than that of either substrate in our media, the reaction almost always approached completion without any significant equilibrium limitations (greater than $95 \%$ conversion in all cases, with the exception of reactions involving methanol, ethanol, or tert-butanol); this observation differs significantly from the effect of water content on the hydrolytic reaction. ${ }^{47}$ These results provide further proof that the reaction takes place at the interface: the water produced apparently partitions to the water pools, away from the sight of reaction. Thus as noted above, lipase must solubilize partly in the interfacial region. The amphiphilic structure of lipase from $C$. cylindracea supports further this claim; in other words, its amino acid content features a larger-than-normal percentage of hydrophobic residues ${ }^{48}$ However, the exact location of the enzyme in the microstructure, which may vary between lipase types as noted above, has yet to be determined.

\section{Enzyme Stability}

Figure 7 contains data for the stability of lipase encapsulated in AOT reverse micelles. For lipases from both $C$. cylindracea and $R$. delemar, enzyme activity decreases more rapidly in reverse micelles than in aqueous solution; but, the degree of deactivation is much less for the former enzyme at low $w_{0}$ values. Moreover, the deactivation of lipase from $C$. cylindracea in reverse micelles at a $w_{0}$ value of 3 [Fig. 7(A)] is not vastly different from that which occurs in aqueous buffer. These results differ from those of Han and Rhee, ${ }^{28}$ who reported stability for lipase from

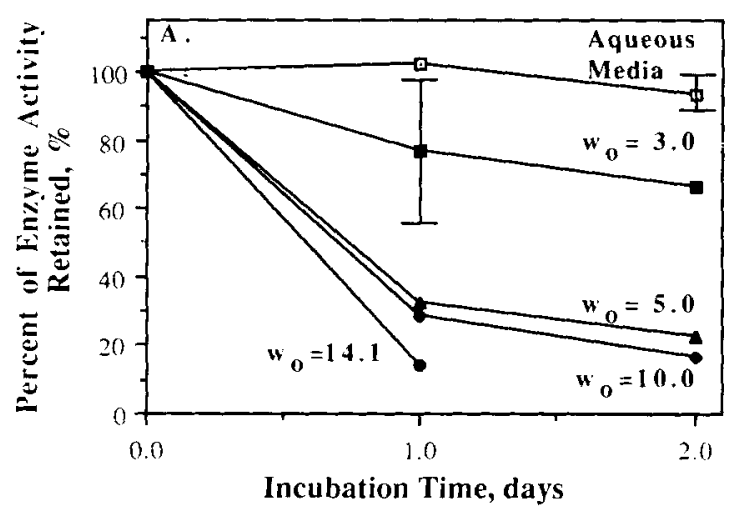

(a)

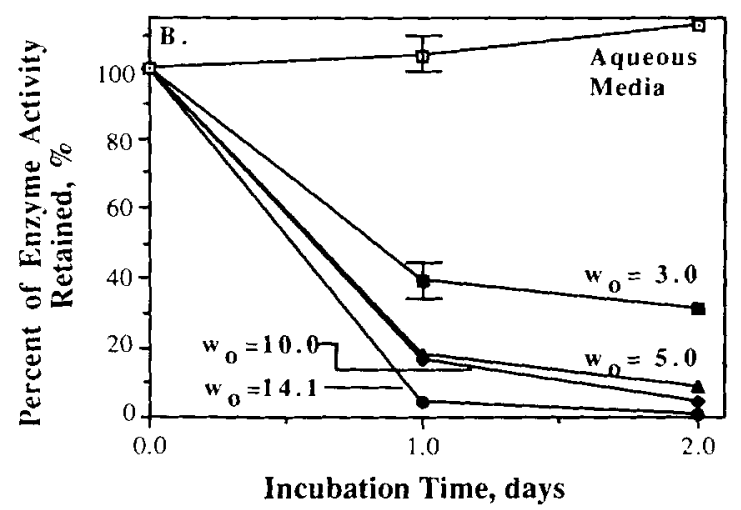

(b)

Figure 7. The effect of $w_{0}$ on the stability of lipase: (A) lipase from $C$. cylindracea; (B) lipase from $R$. delemar; $(\square)$ the stability of lipase in aqueous solution assayed in reverse micelles at $w_{0}=3.0$. The rest of the data corresponds to lipase stability in reverse micelles at $w_{0}$ values listed in the figure. Reaction and substrate concentrations are as in Figure $2 ; \mathrm{pH}_{b}=6.88$. 
C. cylindracea worsened upon changing $w_{0}$ from 5 to 3 . The trend of enhanced stability with smaller micellar size as demonstrated in Figure 7 is generally consistent with other studies of lipases in reverse micelles. ${ }^{11,28}$ However, the degree reverse micelles cause deactivation varies significantly between lipase types, as can be seen from comparison of Figures 7(A) and 7(B) with the study of Fletcher et al. of lipase from Chromobacterium viscosium, ${ }^{11}$ where activity was retained to a much larger degree for $w_{0}$ values between 3 and 56 .

Figure 8 shows that both substrates of reaction I are effective stabilizers for lipase from $R$. delemar. Since both fatty acid and alcohol act as cosurfactants, the size of micelles in substrate-containing incubation mixtures is smaller and this effect may create the enhanced stability by itself, as mentioned above. To determine the effect of micellar size on Figure 8 results, the experiment was repeated with the $R_{h}$ of "empty" incubation mixture reverse micelles, as estimated by DLS, rather than $w_{0}$ held constant. The results for this experiment nearly matched those from the original experiment, indicating that much of the stabilization is related to the actual presence of substrates in the incubation media. (Perhaps a beneficial conformational change in the structure of lipase is induced.) Both fatty acid and alcohol also enhanced the stability of lipase from C. cylindracea. We also examined the role of glycerol and ethylene glycol on stability for lipase from $C$. cylindracea. For reaction I, both alcohols slightly deactivated the enzyme, but for the activity measured by hydrolysis of olive oil (reaction II in the reverse direction), glycerol strongly enhanced stability. Thus, it appears substrates are more effective stabilizers when they are active participants (reactants or products) in the activity-assaying reaction. We have begun a spectroscopic study of lipase in our laboratory to help determine whether enzyme structure is altered in reverse micelles. Moreover, it is quite possible that ionic interactions between the surfactant head group and the enzyme may play a role in the deactivation. ${ }^{49}$

\section{Reaction II: Glyceride Synthesis}

In agreement with Morita et al.,$^{23}$ our results in Figure 9 show that lipase from $R$. delemar can catalyze glyceride synthesis in reverse micelles. Initially, GC analysis shows only the production of 1-monoglycerides and 1,3-diglycerides; this is not surprising since lipase from $R$. delemar is 1,3-positional specific, ${ }^{50}$ meaning it can act only on the outside hydroxyls of glycerol. However, after a week, the appearance of 2-monoglycerides and 1,2-diglycerides was detected, indicating the occurrence of slow, uncatalyzed acyl migrations on glyceride molecules that have been observed elsewhere. ${ }^{16}$ No production of triglycerides was detected. Figure 9 shows how temperature affects product formation for one set of reaction conditions. In all cases, the reaction stopped before completion; the $25^{\circ} \mathrm{C}$ curve on Figure 9 corresponds to ca. 55\% conversion of the limiting reagent: tetradecanoic acid. This premature stoppage was also observed by Fletcher et al. ${ }^{24}$ for lipase from $C$. visco-

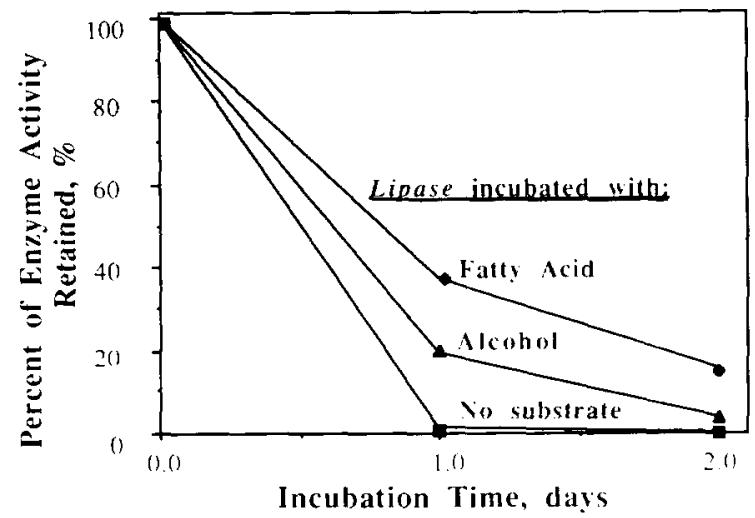

Figure 8. The effect of substrates on the stability of lipase from $R$. delemar at $w_{0}=10.0$ : (a) lipase incubated without substrates; (A) $n$-butanol (250 $\mathrm{m} M$ ) included in incubation mixture; ( $)$ dodecanoic acid $(100 \mathrm{mM})$ in incubation mixture; $w_{0}=10$; reaction and substrate concentrations are as in Figure $2 ; \mathrm{pH}_{b}=6.88$.

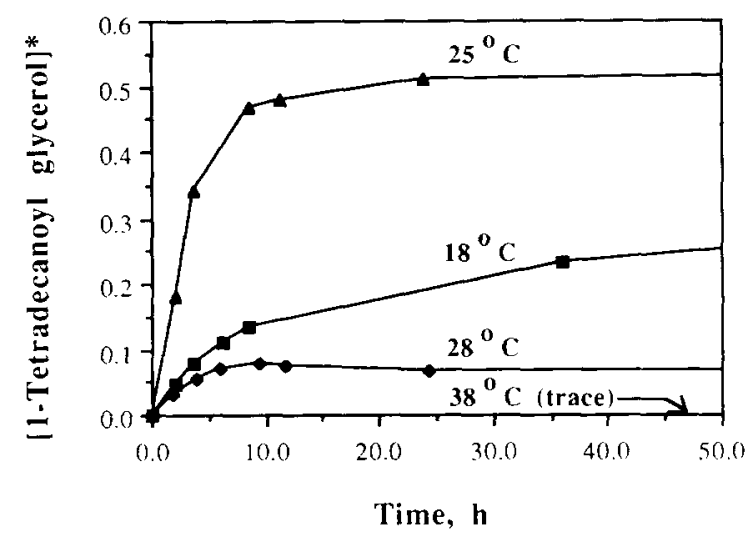

Figure 9. The effect of temperature on glyceride synthesis catalyzed by lipase from $R$. delemar. Temperatures are noted in the figure. The reaction was of type II (see Fig. 1) with tetradecanoic acid and glycerol as substrates: $w_{0}=1.5 ;[$ AOT] $=200 \mathrm{mM} ;$ [Glycerol $]=\left[\mathrm{H}_{2} \mathrm{O}\right]=$ $300 \mathrm{mM}$; [Fatty Acid] $=100 \mathrm{mM} ; \mathrm{pH}_{b}=6.88$. Note: analysis of the same reaction performed at $38^{\circ} \mathrm{C}$ showed only trace amounts of product formation. The asterisk indicates that the concentration of monoglyceride is expressed in terms of gas chromatography peak area: see the Materials and Methods section for more details.

sum, except their reported conversions were higher. Part of the reason for this was the absence of positional specificity by lipase from $C$. viscosum. It appears, as stated by the authors above,$^{24}$ that the stoppage is due to the presence of equilibrium, of which the direct cause has yet to be determined. Our initial work has indicated that, not surprisingly, the concentration of substrates and products (including water) plays a role. Surprisingly, as shown in Figure 9, the production rate and degree of conversion are maximized near room temperature. The primary factor(s) that cause this trend are yet unknown, but may be related to the activity of water ${ }^{21,24}$ and/or the structure of reverse micelles. Thermal deactivation can be safely disregarded as factor since lipase from $R$. delemar is quite thermalstable at temperatures as high as $45^{\circ} \mathrm{C} .{ }^{51}$ A comprehensive study of reaction II pertaining to these issues and others is currently being conducted in our laboratory. 
For lipase from $C$. cylindracea, glyceride synthesis was not achieved in reverse micelles for all ratios of substrates and media components attempted. Although this enzyme has been found to synthesize glycerides in alternate media, ${ }^{21}$ its activity toward this reaction has been reported to be much less than for other fungal and bacterial lipases, with the cause being attributed to deactivation by glycerol. ${ }^{17}$ But as mentioned above, enzyme localization in the surfactant layer away from the water pools, where glycerol resides, may play a role.

\section{CONCLUSIONS}

Important information concerning the activity of lipase in reverse micelles have been obtained. From results of esterification reactions with lipase from $C$. cylindracea, it has been shown that encapsulation in reverse micelles does not change the inherent activity of the enzyme; for example, the $\mathrm{pH}$ profile and the fatty acid substrate specificity remained unchanged. However, the microstructure of the media; moreover, the water/AOT molar ratio and the size, structure, and concentration of substrates and products, had a significant effect on the kinetics observed. Currently, the most important problem of application of reverse micelles with lipases appears to be the rapid loss of enzyme activity that accompanies its employment, which is extreme at intermediate and large micellar size and in the absence of substrate. Further investigation is needed to determine the cause of the activity loss. Lipase from $R$. delemar catalyzed the synthesis of glycerides in reverse micelles at conversions of less than $60 \%$, with results showing the rate and the percent conversion are linked to temperature and concentrations of substrates and products (including water). The underlying cause of early termination for the reaction appears to be related to kinetic equilibrium, with micellar structural properties and the activity of water also possibly having a role. Lipase from C. cylindracea did not catalyze glyceride formation perhaps due to glycerol-enhanced deactivation or unfavorable localization within the micellar microstructure.

Financial support for this project by the National Science Foundation Grant \#CBT 87-01718 is gratefully acknowledged. Also, we are indebted to Mr. F. Parker of the Department of Chemistry at the University of Michigan for his kind assistance with the ${ }^{31}$ P-NMR work.

\section{References}

1. H. F. Eicke in Interfacial Phenomena in Apolar Media: Surfactant Science Series, Vol. 21, H. F. Eicke and G. D. Parfitt, Eds. (Marcel Dekker, New York, 1987), p. 41.

2. P. L. Luisi and L. J. Magid, CRC Crit. Rev. Biochem., 20, 409 (1986).

3. D. Langevin in Reverse Micelles: Biological and Technological Relevance of Amphiphilic Structure in Apolar Media, P. L. Luisi and B. E. Straub, Eds. (Plenum, New York, 1984), p. 287.

4. C. Tondre and A. Xenaksis in Surfactants in Solution, Vol. 3, K. L. Mittal and R. Lindman, Eds. (Plenum, New York, 1984), p. 1881.

5. K. E. Göklen and T. A. Hatton, Biotechnol. Prog., 1, 69 (1985).
6. P. Speiser in Reverse Micelles: Biological and Technological Relevance of Amphiphilic Structure in Apolar Media, P. L. Luisi and B. E. Straub, Eds. (Plenum, New York, 1984), p. 339.

7. Y. L. Khmel'nitskii, A. V. Levashov, N. L. Klyachko, and K. Martinek, Russ. Chem. Reviews., 53, 319 (1984).

8. P. L. Luisi, Angew. Chemie, 24, 439 (1985).

9. R. Hilhorst, C. Laane, and C. Veeger, FEBS Lett., 159, 225 (1983).

10. E. A. Malakhova, B. I. Kurganov, A. V. Levashov, I. V. Berezin, and K. Martinek, Dokl. Akad. Nauk. S.S.S.R. Biochem., (in English), 270, 182 (1983).

11. P. D. I. Fletcher, B.H. Robinson, R. B. Freedman, and C. Oldfield, J. Chem. Soc. Faraday Trans. I, 81, 2667 (1985).

12. C. J. O'Connor, I. C. Stockley, and P. Walde, Aust. J. Chem., 39, 2937 (1986).

13. B. H. Munk, European Patent No. 0-177-183, September 4, 1986.

14. M. H. Memon and P. J. Worsfold, Anal. Proc., 23, 269 (1986).

15. D. Han, D. Y. Kwon, and J. S. Rhee, Agric. Biol. Chem., 71, 615 (1987).

16. A. R. Macrae, J. Am. Oil Chem. Soc., 60, 243A (1983).

17. M. M. Hoq, H. Tagami, T. Yamane, and S. Shimizu, Agric. Biol. Chem., 49, 335 (1985).

18. K. Yokozeki, T. Tanaka, S. Yamanaka, T. Takinami, Y. Hirose, K Sonomoto, A. Tanaka, and S. Fukui in Enzyme Engineering: Vol. 6 , I. Chibata, S. Fukui, and L. B. Wingard, Eds. (Plenum, New York, 1982), p. 151.

19. K. Holmberg, and E. Österberg, European Patent No. 0-237-092, September 16, 1987.

20. K. Holmberg, and E. Österberg, Prog. Colloid Polymer Sci., 74, 98 (1987).

21. M. Bello, D. Thomas, and M. D. Legoy, Biochem. Biophys. Res. Comm., 146, 361 (1987)

22. G. Abraham, M. A. Murray, and V.T. John, Biotechnol. Lett., 10, 555 (1988).

23. S. Morita, H. Narita, T. Matoba, and M. Kito, J. Am. Oil Chem. Soc., 61, 1571 (1984).

24. P. D. I. Fletcher, R. B. Freedman, B. H. Robinson, G. D. Rees, and R. Schomacker, Biochem. Biophys. Acta, 913, 278 (1987).

25. C. A. Martin and L. J. Magid, J. Phys. Chem., 85, 3938 (1981).

26. W. B. Bedwell, Ph.D. thesis, The University of Michigan, Ann Arbor, MI, 1983

27. R. R. Lowry ans1035I Tinsley, J. Am. Oil Chem. Soc., 53, 470 (1976).

28. D. Han and J. S. Rhee, Biotechnol. Bioeng., 28, 1250 (1986).

29. D. A. Brengartner, Anal. Chim. Acta, 173, 177 (1985).

30. F. J. Bonner and P. L. Luisi, J. Solid-Phase Biochem., 5, 255 (1980).

31. N. C. Ford Jr. in Dynamic Light Scattering: Applications of Photon Correlation Spectroscopy, R. Pecora, Ed. (Plenum, New York, 1985), p. 7.

32. R. Pecora, J. Chem. Phys., 40, 1604 (1964).

33. J.D. Nicholson, J.R. Doherty, and J.H. R. Clarke in Microemulsions, E. D. Robb, Ed. (Plenum, New York, 1984), p. 1533.

34. D. E. Koppel, J. Chem. Phys., 57, 4814 (1972).

35. R. E. Smith and P. L. Luisi, Helv. Chim. Acta, 63, 2302 (1980).

36. H. Fujii, T. Kawai, H. Nishikawa, and G. Ebert, Colloid Polymer Sci., 260, 697 (1982)

37. G. Benzonana and S. Esposito, Biochem. Biophys. Acta., 231, 15 (1970).

38. N. Tomizuka, Y. Ota, and K. Yamada, Agric. Biol. Chem., 30, 576 (1966).

39. P. L. Luisi, P. Meier, V.E. Imre, and A. Pande in Reverse Micelles: Biological and Technological Relevance of Amphiphilic Structure in Apolar Media, P. L. Luisi and B. E. Straub, Eds. (Plenum, New York, 1984), p. 323.

40. E. Sheu, K. E. Göklen, T. A. Hatton, and S. H. Chen, Biotechnol. Prog., 2, 175 (1986).

41. G. Zampieri, H. Jackle, and P. L. Luisi, J. Phys. Chem., 90, 1849 (1989).

42. M. Clausse, J. Peyrelasse, C. Boned, J. Heil, L. Nicolas-Morgantini, and A. Zradbva in Surfactants in Solution, Vol. 3, K. L. Mittal and B. Lindman, Eds., (Plenum, New York, 1984), p. 1745. 
43. R. T. Morrison and R. N. Boyd, Organic Chemistry (4th ed.) (Allyn and Bacon, Boston, 1983).

44. V. K. Bansul, D. O. Shah, and J. P. O'Connell, J. Colloid Interf. Sci., 75, 462 (1980).

45. S. Okumura, M. Iwai, and Y. Tsujisaka, Biochem. Biophys. Acta, 575, $156(1979)$.

46. E. Sjoblom, U. Henriksson, and P. Stilbs in Reverse Micelles: Biological and Technological Relevance of Amphiphilic Structures in Apolar Media, P. L. Luisi and B.E. Straub, Eds. (Plenum, New York, 1984), p. 131.
47. D. Han, J. S. Rhee, and S. B. Lee, Biotechnol. Bioeng., 30, 381 (1987).

48. N. Tomizuka, Y. Ota, and L. Yamada, Agric. Biol. Chem., 30, 1090 (1966).

49. B. Steinmann, H. Jäckle, and P. L. Luisi, Biopolymers, 25, 1133 (1986).

50. Y. Tsujisaka, S. Okumura, and M. Iwai, Biochem. Biophys. Acta, 489, 415 (1977).

51. M. Iwai and Y. Tsujisaka, Agric. Biol. Chem., 38, 1241 (1974). 